\title{
Pola Peresepan Penyakit Stroke Iskemik Pasien Rawat Jalan Rumah Sakit di Kota Sungailiat
}

\author{
Lana Sari $^{*}$, Ronal Worthy ${ }^{2}$, dan Dela Lanaya ${ }^{3}$ \\ 1. Jurusan Farmasi- Poltekkes Kemenkes Pangkalpinang \\ 2. Jurusan Farmasi- Poltekkes Kemenkes Pangkalpinang \\ 3. Jurusan Farmasi- Poltekkes Kemenkes Pangkalpinang \\ *Email Korespondensi: lanasari28@gmail.com
}

\begin{abstract}
Abstrak
Stroke merupakan salah satu penyakit tidak menular (PTM) yang menyebabkan kecacatan nomor satu di dunia. Data Riskesdas 2018 melaporkan bahwa penderita stroke di Provinsi Bangka Belitung meningkat menjadi $>10,9 \%$ di atas rata-rata penderita penyakit stroke di Indonesia. Penelitian ini bertujuan mengetahui gambaran pola peresepan stroke iskemik yang dapat dijadikan salah satu sumber informasi dalam perencanaan dan pengadaan obat Rumah Sakit di Kota Sungailiat dalam upaya meningkatkan pelayanan kesehatan. Rancangan penelitian ini observasional deskriptif retrospektif. Hasil penelitian menunjukkan obat stroke iskemik yang sering digunakan adalah citicoline $500 \mathrm{mg}$ sebanyak $22 \%$, bentuk sediaan berupa tablet sebanyak $100 \%$, kekuatan sediaan citicoline $500 \mathrm{mg} 29,6 \%$, dosis obat clopidogrel $75 \mathrm{mg}$ perhari 18,4\%, jumlah obat yaitu 2 jenis yaitu $61,3 \%$, untuk aturan pemakaian yaitu clopidogrel $75 \mathrm{mg}$ digunakan $1 \times 118,4 \%$ dan cara penggunaan dengan oral sebanyak $100 \%$. Pola peresepan stroke iskemik pasien rawat jalan Rumah Sakit di Kota Sungailiat tahun 2018 sudah sesuai dengan guidelines. Penelitian lebih lanjut untuk pola peresepan penyakit stroke iskemik dan penyakit tidak menular (PTM) lainnya bisa menggunakan metode prospektif.
\end{abstract}

Kata kunci: pola peresepan, stroke iskemik, rawat jalan

\section{Prescribing Patterns of Ischemic Stroke Outpatients Hospital in Sungailiat City}

\begin{abstract}
Stroke is one of the non-communicable diseases (PTM) which is the number one cause of disability in the world. Riskesdas 2018 data reported that stroke patients in Bangka Belitung Province increased to> 10.9\% above the average stroke sufferers in Indonesia. This research is intended to find out the description of ischemic stroke prescribing patterns that can be used as a source of information in the planning and procurement drugs in hospital City of Sungailiat and try to improve health services. This study used a retrospective descriptive observational study design. The results showed that the drugs that frequently used citicoline $500 \mathrm{mg} 22 \%$, dosage forms that widely used tablets $100 \%$, the strength of the dosage that widely used citicoline $500 \mathrm{mg} 29.6 \%$, large drug doses $75 \mathrm{mg}$ per day 18.4\%, amount of drugs 2 types $61.3 \%$, the rule of clopidogrel $75 \mathrm{mg}$ used $1 \times 118.4 \%$ and the use with oral $100 \%$. The pattern of prescribing ischemic stroke for outpatients at the Hospital in Sungailiat City in 2018 changes the wording ischemic stroke guidelines. Further research for prescribing patterns of ischemic stroke and other noncommunicable diseases (PTM) can use prospective methods.
\end{abstract}

Keywords: prescribing, ischemic stroke, outpatient 


\section{PENDAHULUAN}

Penyakit tidak menular (PTM) merupakan penyakit kronis yang tidak ditularkan dari orang ke orang lain. PTM merupakan penyebab kematian hampir $70 \%$ di dunia (Kemenkes RI, 2017). Data PTM dalam Riskesdas 2013 meliputi: penyakit asma, penyakit paru obstruksi kronis (PPOK), kanker, DM, hipertiroid, hipertensi, jantung koroner, gagal jantung, stroke, gagal ginjal kronis, batu ginjal, penyakit sendi/ rematik. Stroke merupakan penyebab kecacatan nomor satu di dunia, penyebab kematian nomor dua di dunia (Fagan dan Hess, 2008).

Data yang diperoleh dari hasil Riset Kesehatan Dasar (Riskesdas) pada tahun 2013, sebanyak 9,7\% masyarakat Bangka Belitung terdiagnosis stroke dan $14,6 \%$ terdiagnosis dan memiliki gejala meningkat seiring dengan bertambahnya umur terkait penyakit stroke (Kemenkes RI, 2013). Pada tahun 2018 Riskesdas 2018 melaporkan bahwa penderita stroke di Provinsi Bangka Belitung meningkat menjadi > $10,9 \%$ di atas rata-rata penderita penyakit stroke di Indonesia. Oleh karena itu perlu adanya peningkatan pelayanan kesehatan yang salah satu variabel yang perlu dilakukan menurut rekomendasi World Health Organization (WHO) (1993) adalah pola peresepan.

Pola peresepan merupakan gambaran peresepan obat-obatan yang digunakan dalam mengobati penyakit dalam suatu resep Pola peresepan digunakan sebagai indikator inti untuk mengukur tingginya tingkat pelayanan kesehatan. Komponen pola peresepan tersebut terdiri dari nama obat, bentuk sediaan obat, kekuatan sediaan, dosis obat, jumlah obat yang diberikan, aturan pemakaian dan cara penggunaan obat.

Pola peresepan penting dilakukan agar tidak terjadi peresepan obat yang salah sehingga nantinya akan mengakibatkan pengobatan obat yang tidak rasional (medication error). Pola peresepan yang tidak rasional akan meningkatkan terjadinya efek samping obat, interaksi obat, biaya pengobatan meningkat serta mengakibatkan penurunan kepatuhan pasien dalam mengkonsumsi obat. Ketidakrasionalan juga dapat berpengaruh pada fisiologi pasien karena obat-obat yang diberikan secara berlebihan baik berdasarkan indikasi maupun dosis akan membahayakan fungsi organ tubuh (Destiani et al, 2016).

Berdasarkan hasil wawancara dengan apoteker penanggung jawab Instalasi Farmasi Rawat Jalan Rumah Sakit di Kota Sungailiat didapatkan informasi bahwa kurang lebih $60 \%$ pasien rawat jalan yang berobat ke rumah sakit tersebut berobat ke poli penyakit saraf setiap hari. Pasien-pasien tersebut sudah terdiagnosis penyakit stroke iskemik yang berobat rutin. Obat yang digunakan dalam pengobatan di poli penyakit saraf biasanya habis sebanyak lebih dari 300 butir per hari sehingga sering terjadi kekosongan obat di instalasi farmasi tersebut. Pada tahun 2016 jumlah resep yang diresepkan untuk pasien yang terdiagnosis stroke iskemik kurang lebih 538 resep. Tahun selanjutnya terjadi penurunan jumlah resep tetapi perbedannya tidak terlalu signifikan dimana jumlah resep untuk pasien yang terdiagnosis stroke iskemik pada tahun 2017 kurang lebih 512 resep. Tahun 2018 jumlah resep untuk pasien yang terdiagnosa stroke iskemik meningkat menjadi kurang lebih 1565 resep, terjadi peningkatan yang sangat signifkan menjadi 2 kali lipat dari jumlah resep tahun sebelumnya (Ferlyanti, 2019).

Tujuan penelitian ini adalah untuk mengetahui gambaran pola peresepan stroke iskemik yang dapat dijadikan salah satu sumber informasi dalam perencanaan dan pengadaan obat Rumah Sakit di Kota Sungailiat dalam upaya meningkatkan pelayanan kesehatan. Hasil penelitian ini dapat dijadikan bahan referensi terhadap pelayanan resep bagi pasien stroke iskemik Rumah Sakit di Kota Sungailiat.

\section{METODE}

Jenis penelitian ini adalah penelitian bersifat deskriptif kuantitatif dengan pendekatan retrospektif. Penelitian ini dilakukan di Rumah Sakit di Kota Sungailiat bulan Januari-Juni 2019. Populasi dalam penelitian ini adalah semua resep pasien rawat jalan yang terdiagnosis penyakit stroke iskemik dari bulan Januari-Desember tahun 2018 yang berjumlah 339 resep. 
Besar sampel pada penelitian ini dihitung menggunakan rumus besar sampel data proporsi dengan syarat populasi diketahui (Riyanto, 2011). Instrumen yang digunakan dalam penelitian ini berupa resep penyakit stroke iskemik pada pasien rawat jalan di Rumah Sakit di Kota Sungailiat Tahun 2018.

\section{HASIL}

Hasil telaah resep terkait pola peresepan berupa nama obat, bentuk sediaan, kekuatan sediaan, dosis obat, jumlah obat, aturan pemakaian dan cara penggunaan yang sering digunakan pada penyakit stroke iskemik di Rumah Sakit di Kota Sungailiat terurai seperti di bawah ini:

\section{Nama Obat}

Nama obat yang digunakan untuk pasien stroke iskemik tercantum pada Tabel 1 yang menunjukkan nama obat yang paling banyak digunakan untuk pasien stroke iskemik adalah citicoline dengan kekuatan sediaan 500 mg sebanyak 74 lembar resep dengan persentase $22 \%$.

Tabel 1. Nama Obat yang Digunakan untuk Pasien Stroke Iskemik

\begin{tabular}{clcc}
\hline No & \multicolumn{1}{c}{ Nama Obat } & Jumlah (resep) & Persentase (\%) \\
\hline $\mathbf{1}$ & Citicoline 500 mg & 74 & 22 \\
$\mathbf{2}$ & Piracetam 800 mg & 47 & 13,8 \\
$\mathbf{3}$ & Clopidogrel 75 + Citicoline 500 mg & 44 & 13 \\
$\mathbf{4}$ & Clopidogrel 75 mg + Piracetam $800 \mathrm{mg}$ & 37 & 11 \\
$\mathbf{5}$ & Cilostazol 50 mg + Piracetam $800 \mathrm{mg}$ & 32 & 9,4 \\
$\mathbf{6}$ & Aspirin 80 mg + Piracetam 800 mg & 20 & 6 \\
$\mathbf{7}$ & Aspirin 80 mg + Citicoline 500 mg & 16 & 4,7 \\
$\mathbf{8}$ & Clopidogrel 75 mg + Piracetam 1200 mg & 15 & 4,4 \\
$\mathbf{9}$ & Cilostazol 50 mg + Citicoline 500 mg & 14 & 4,1 \\
$\mathbf{1 0}$ & Aspirin 80 mg + Piracetam 1200 mg & 10 & 3 \\
$\mathbf{1 1}$ & Piracetam 1200 mg & 8 & 2,3 \\
$\mathbf{1 2}$ & Cilostazol 100 mg + Citicoline 500 mg & 8 & 2,3 \\
$\mathbf{1 3}$ & Cilostazol 100 mg + Piracetam 800 mg & 6 & 1,7 \\
$\mathbf{1 4}$ & Clopidogrel 75 mg + Citicoline 500 mg + & 3 & 0,8 \\
& Piracetam 1200 mg & & 0,6 \\
$\mathbf{1 5}$ & Citicoline 500 mg + Piracetam 1200 mg & 2 & 0,3 \\
$\mathbf{1 6}$ & Cilostazol 50 mg + Citicoline 500 mg + & 1 & \\
& Piracetam 800 mg & & 100 \\
\hline
\end{tabular}

Sumber: Data Primer, 2018

\section{Bentuk Sediaan}

Bentuk sediaan yang digunakan pasien stroke iskemik adalah sediaan padat sebanyak 339 lembar resep (100\%).

\section{Kekuatan Sediaan}

Kekuatan sedian yang digunakan untuk pasien stroke iskemik tercantum pada Tabel 2, yang menunjukkan kekuatan sediaan yang paling banyak digunakan untuk pasien stroke iskemik adalah obat citicoline dengan kekuatan sediaan $500 \mathrm{mg}$ sebanyak 165 item obat dengan persentase $29,6 \%$.
Tabel 2. Kekuatan Sediaan yang Digunakan Untuk Pasien Stroke Iskemik

\begin{tabular}{llccc}
\hline No & Nama Obat & $\begin{array}{c}\text { Kekuatan } \\
\text { Sediaan }\end{array}$ & $\begin{array}{c}\text { Jum- } \\
\text { lah }\end{array}$ & $\begin{array}{c}\text { Persen- } \\
\text { tase (\%) }\end{array}$ \\
\hline $\mathbf{1}$ & Citicoline & $500 \mathrm{mg}$ & 165 & 29,6 \\
$\mathbf{2}$ & Piracetam & $800 \mathrm{mg}$ & 145 & 26 \\
$\mathbf{3}$ & Clopidogrel & $75 \mathrm{mg}$ & 100 & 18 \\
$\mathbf{4}$ & Cilostazol & $50 \mathrm{mg}$ & 48 & 8,7 \\
$\mathbf{5}$ & Aspirin & $80 \mathrm{mg}$ & 46 & 8,3 \\
$\mathbf{6}$ & Piracetam & $1200 \mathrm{mg}$ & 39 & 7 \\
$\mathbf{7}$ & Cilostazol & $100 \mathrm{mg}$ & 13 & 2,4 \\
\hline & & Total & 556 & 100 \\
\hline
\end{tabular}

Sumber: Data Primer, 2018 


\section{Dosis Obat}

Dosis obat yang digunakan untuk pasien stroke iskemik tersedia pada Tabel 3 menunjukkan dosis yang paling banyak digunakan untuk pasien stroke iskemik adalah clopidogrel $75 \mathrm{mg}$ dengan dosis (per hari) adalah $75 \mathrm{mg}$ sebanyak 100 item obat dengan persentase $18,4 \%$.

Tabel 3. Dosis Obat yang Digunakan untuk Pasien Stroke Iskemik

\begin{tabular}{llccc}
\hline No & Nama Obat & $\begin{array}{c}\text { Dosis } \\
\text { Obat } \\
\text { (per hari) }\end{array}$ & $\begin{array}{c}\text { Jum- } \\
\text { lah }\end{array}$ & $\begin{array}{c}\text { Persen } \\
\text {-tase } \\
(\boldsymbol{\%})\end{array}$ \\
\hline $\mathbf{1}$ & Clopidogrel 75 & $75 \mathrm{mg}$ & 100 & 18,4 \\
& mg & & & \\
$\mathbf{2}$ & Citicoline 500 mg & $1000 \mathrm{mg}$ & 85 & 15,5 \\
$\mathbf{3}$ & Citicoline 500 mg & $500 \mathrm{mg}$ & 80 & 14,6 \\
$\mathbf{4}$ & Piracetam 800 mg & $800 \mathrm{mg}$ & 76 & 14 \\
$\mathbf{5}$ & Piracetam 800 mg & $1600 \mathrm{mg}$ & 64 & 11,8 \\
$\mathbf{6}$ & Cilostazol 50 mg & $50 \mathrm{mg}$ & 48 & 8,8 \\
$\mathbf{7}$ & Aspirin 80 mg & $80 \mathrm{mg}$ & 46 & 8,4 \\
$\mathbf{8}$ & Piracetam 1200 & $1200 \mathrm{mg}$ & 34 & 6,2 \\
& mg & & 13 & 2,3 \\
$\mathbf{9}$ & Cilostazol 100 mg & $100 \mathrm{mg}$ & 13 & \\
\hline & & Total & 546 & 100 \\
\hline
\end{tabular}

Sumber: Data Primer, 2018

\section{Jumlah Obat}

Jumlah obat yang digunakan untuk pasien stroke iskemik pada Tabel 4 menunjukkan jumlah obat yang yang paling banyak digunakan untuk pasien stroke iskemik adalah 2 macam sebanyak 206 lembar resep dengan persentase $60,7 \%$.

Tabel 4. Jumlah Obat yang Digunakan untuk Pasien Stroke Iskemik

\begin{tabular}{cccc}
\hline No & $\begin{array}{c}\text { Jumlah Obat } \\
\text { (macam) }\end{array}$ & $\begin{array}{c}\text { Jumlah } \\
\text { Resep }\end{array}$ & $\begin{array}{c}\text { Persentase } \\
(\boldsymbol{\%})\end{array}$ \\
\hline $\mathbf{1}$ & 2 & 206 & 60,7 \\
$\mathbf{2}$ & 1 & 129 & 38,1 \\
$\mathbf{3}$ & 3 & 4 & 1,2 \\
\hline & Total & 339 & 100 \\
\hline
\end{tabular}

Sumber: Data Primer, 2018

\section{Aturan Pemakaian}

Aturan pemakaian yang digunakan untuk pasien stroke iskemik pada Tabel 5 menunjukkan aturan pemakaian yang paling sering digunakan untuk pasien stroke iskemik adalah clopidogrel $75 \mathrm{mg}$ dengan aturan pemakaian 1 kali sehari sebanyak 100 item obat dengan persentase $18,4 \%$.
Tabel 5. Aturan Pemakaian yang Digunakan untuk Pasien Stroke Iskemik

\begin{tabular}{llccc}
\hline No & $\begin{array}{l}\text { Nama Obat dan } \\
\text { Kekuatan } \\
\text { Sediaan }\end{array}$ & $\begin{array}{c}\text { Aturan } \\
\text { Pemakai } \\
\text { an }\end{array}$ & $\begin{array}{c}\text { Jum- } \\
\text { lah }\end{array}$ & $\begin{array}{c}\text { Perse } \\
\text { ntase } \\
\text { (\%) }\end{array}$ \\
\hline $\mathbf{1}$ & $\begin{array}{l}\text { Clopidogrel 75 } \\
\text { mg }\end{array}$ & $1 \times 1$ & 100 & 18,4 \\
$\mathbf{2}$ & Citicoline 500 mg & $2 \times 1$ & 85 & 15,5 \\
$\mathbf{3}$ & Citicoline 500 mg & $1 \times 1$ & 80 & 14,6 \\
$\mathbf{4}$ & Piracetam 800 mg & $1 \times 1$ & 76 & 14 \\
$\mathbf{5}$ & Piracetam 800 mg & $2 \times 1$ & 64 & 11,8 \\
$\mathbf{6}$ & Cilostazol 50 mg & $1 \times 1$ & 48 & 8,8 \\
$\mathbf{7}$ & Aspirin 80 mg & $1 \times 1$ & 46 & 8,4 \\
$\mathbf{8}$ & Piracetam 1200 & $1 \times 1$ & 34 & 6,2 \\
& mg & & & \\
$\mathbf{9}$ & Cilostazol 100 mg & $1 \times 1$ & 13 & 2,3 \\
\hline & & Total & 546 & 100 \\
\hline
\end{tabular}

Sumber: Data Primer, 2018

\section{Cara Penggunaan}

Cara penggunaan obat yang digunakan untuk pasien stroke iskemik adalah dengan cara oral. Dalam penelitian ini resep yang ditelaah merupakan resep pasien rawat jalan sehingga obat yang diresepkan semuanya dengan cara pemakaian oral.

\section{PEMBAHASAN}

Penelitian yang telah dilakukan menunjukkan gambaran pola peresepan penyakit stroke iskemik pada pasien rawat jalan di Rumah Sakit di Kota Sungailiat tahun 2018 menunjukkan hasil bahwa nama obat yang paling banyak digunakan adalah citicoline 500 mg. Penelitian yang dilakukan sejalan dengan penelitian Praja et al (2013) yang menyatakan pemakaian citicoline dalam dosis tunggal sebanyak 93,14\% dari sampel yang digunakan.

Citicoline adalah obat yang masuk kedalam golongan neuroprotektif yang bertujuan untuk menghambat proses kerusakan pada neuron yang tidak mampu menghasilkan potensial aksi. Saat jaringan mengalami iskemia, terjadi insufisiensi energi untuk menjaga fungsi membran secara normal. Obat golongan neuroprotektif diberikan agar natrium tidak berdifusi ke dalam sel yang menyebabkan depolarisasi membran sel (Wahjoepramono, 2005). Peran citicoline sebagai neuroprotektan pada level neuronal adalah memperbaiki membran sel dengan cara menambah sintesis phosphatidylcholine yang merupakan komponen utama membran sel terutama otak. Meningkatnya sintesis phosphatidylcholine akan berpengaruh pada perbaikan fungsi 
membran sel yang mengarah pada perbaikan sel. Selain itu, kolin dalam sitikolin merupakan prekursor asetilkolin yaitu neurotransmitter yang penting untuk fungsi kognitif (Praja et al, 2013). Citicoline yang penggunaannya sebagai neuroprotektor juga telah banyak dilakukan penelitian terkait efektivitasnya. Review dari 13 clinical trial menyatakan bahwa penggunaan citicoline pada stroke iskemik dan gangguan CNS meningkatkan fungsi neurologis dan dapat mempercepat penyembuhan pasien (Adibhatla dan Hatcher, 2005).

Penelitian yang telah dilakukan ini sejalan dengan penelitian yang dilakukan oleh Febriola (2019) yang menyatakan citicoline merupakan obat paling banyak digunakan untuk pasien stroke iskemik dengan persentase 98,33\%. Pemberian neuroprotektif ini bertujuan agar sisi otak yang mengalami iskemik tidak berubah menjadi infark (Presley, 2014).

Selain itu, Piracetam juga menjadi pilihan kedua terbanyak. Penelitian mengenai pemberian piracetam untuk rehabilitasi pasien afasia pasca stroke dan untuk aktivasi aliran darah memperoleh hasil bahwa piracetam meningkatkan rehabilitasi/ recovery dari fungsi bahasa pasien pasca stroke dan meningkatkan aktivasi aliran darah secara signifikan (Kessler dkk., 2000).

Penelitian yang dilakukan oleh Mahapatra dkk. (2008) menunjukkan bahwa piracetam diketahui mempunyai efek terhadap aliran darah otak dengan menurunkan adhesi, agregasi dan deformabilitas eritrosit sehingga memperbaiki perfusi darah ke otak. Hasil analisis statistik menunjukkan bahwa pasien stroke iskemik yang mendapat terapi piracetam selama 7 hari berdasarkan total domain menunjukkan adanya perbaikan fungsi kognitif yang bermakna 0,000 $(\mathrm{p}<0,05)$ (Wahyuddin et al, 2013).

Bentuk sediaan yang digunakan adalah sediaan padat berupa tablet. penderita stroke iskemik pada pasien rawat jalan di Rumah Sakit di di Kota Sungailiat tergolong dalam usia dewasa sehingga penggunaan bentuk sediaan tablet lebih dianjurkan karena sediaan tablet mempunyai keuntungan seperti memiliki ketepatan dosis setiap unit tablet, sediaan lebih stabil dan tidak mudah ditumbuhi mikroba karena memiliki kadar air yang sangat rendah, mudah dibawa, dapat digunakan tanpa bantuan medis, bau dan rasa yang tidak enak dapat ditutupi dengan penyalutan (Ansel, 2008).

Citicoline dengan kekuatan sediaan 500 mg merupakan kekuatan obat yang paling banyak digunakan pada penelitian ini, hal tersebut sesuai dengan pemberian citicoline sebagai neuroprotektif paling banyak adalah kekuatan sediaan $500 \mathrm{mg}$. Dosis obat citicoline yang digunakan pada pasien stroke iskemik adalah $50 \mathrm{mg}-1000 \mathrm{mg}$ perhari dan dapat digunakan 2 sampai 3 kali sehari (PERDOSSI, 2011). Citicoline dengan kekuatan sediaan 500 $\mathrm{mg}$ ini paling banyak digunakan untuk pengobatan stroke iskemik karena kekuatan sediaan ini mempermudah pemberian obat sesuai dengan dosis yang ditetapkan.

Dosis obat yang paling banyak digunakan adalah Clopidogrel 75 mg digunakan 1 kali sehari diikuti dengan citicoline $500 \mathrm{mg}$ digunakan 2 kali sehari. Pemberian obat clopidogrel dengan kekuatan sediaan $75 \mathrm{mg}$ dalam penelitian ini diberikan satu kali sehari sehingga dosis yang digunakan oleh penderita stroke iskemik adalah $75 \mathrm{mg}$ perhari. Pemberian dosis ini sesuai dengan PERDOSSI (2011) yang menyatakan bahwa pemberian obat clopidogrel pada pasien stroke iskemik adalah $75 \mathrm{mg}$ peroral sekali sehari. Pemberian obat citicoline dengan kekuatan sediaan $500 \mathrm{mg}$ dalam penelitian ini paling banyak diberikan dua kali sehari sehingga dosis yang digunakan oleh penderita stroke iskemik adalah $1000 \mathrm{mg}$ perhari. Pemberian dosis ini sesuai dengan PERDOSSI (2011) yang menyatakan bahwa pemberian citicoline untuk pasien stroke iskemik adalah $500 \mathrm{mg}-1000$ mg perhari dan dapat diberikan 2 kali perhari.

Dosis citicolin yang direkomendasikan untuk pasien stroke iskemik adalah $2 \times 1000 \mathrm{mg}$ melalui rute intravena selama 3 hari, kemudian terapi dilanjutkan selama 3 minggu dengan rute oral dan dosis 2x1000 mg (PERDOSSI, 2011). Penggunaan citicolin (500 mg peroral setiap hari) selama 6 minggu aman diberikan pada pasien stroke iskemik namun tidak efektif untuk memperbaiki outcome pasien (Clark et al, 1999).

Jumlah obat merupakan banyaknya obat yang diberikan yang dilihat dari macamnya. Berdasarkan tabel 4 jumlah obat yang digunakan untuk pasien stroke iskemik di Rumah Sakit di Kota Sungailiat tahun 2018 
yang paling banyak digunakan adalah dua macam obat. Menurut Wahjoepramono (2005) terapi spesifik stroke iskemik dilakukan dengan cara memberikan obat golongan Trombolisis rtPA, Trombolitik Intra-Arterial, Antikoagulan, Antiplatelet dan Neuroprotektif. Penelitian yang dilakukan ini mendapatkan hasil bahwa sebagian besar resep pengobatan stroke adalah obat sebagai antiplatelet dan neuroprotektif.

Salah satu dampak yang ditimbulkan stroke berupa gangguan kognitif. Neuroprotektor seperti piracetam dan citikoline merupakan obat yang dapat mengatur fungsi serebral dengan meningkatkan kemampuan kognitif pada otak yang menurun, namun penggunaannya masih kontroversial dan menjadi perdebatan berdasarkan penelitian ilmiah. Namun penggunaan kedua neuroprotektor yaitu piracetam dan citikoline di beberapa rumah sakit di Makassar masih banyak digunakan pada pasien stroke iskemik (Wahyuddin et al, 2013).

Berbagai penelitian tentang efektivitas pemberian antiplatelet sebagai terapi pencegahan stroke berulang telah dilakukan, antara lain penelitian di Cina menunjukkan bahwa pemberian kombinasi aspirin dan clopidogrel lebih efektif dalam mencegah stroke berulang dibandingkan dengan aspirin tunggal $(8,2 \%$ vs $11,7 \%)$, namun tidak meningkatkan risiko pendarahan (Wang et al., 2013). Hasil penelitian antiplatelet treatment for prevention of cerebrovascular event in patient with vascular disease a systematic review and meta analysis menunjukkan kombinasi terapi aspirin dan klopidogrel efektif menurunkan risiko stroke iskemik dibandingkan aspirin tunggal sebesar 20\% (Gouya et al., 2014).

Aturan pemakaian yang paling sering digunakan untuk penyakit stroke iskemik untuk pasien rawat jalan di Rumah Sakit di Kota Sungailiat tahun 2018 yaitu clopidogrel dengan dosis $75 \mathrm{mg}$ diberikan 1 kali sehari 1 tablet. Aturan pemakaian pada obat clopidogrel $75 \mathrm{mg}$ ini disesuaikan dengan dosis yang dibutuhkan penderita stroke iskemik. Pemberian obat clopidogrel sebagai antiplatelet yaitu $75 \mathrm{mg}$ secara oral per hari (PERDOSSI, 2011). Penggunaan aturan pemakaian terhadap golongan neuroprotektif juga sama halnya golongan antiplatelet. Obat golongan neuroprotektif yang paling banyak digunakan dalam penelitian ini adalah citicoline dengan kekuatan sediaan $500 \mathrm{mg}$ diberikan 2 kali dalam sehari sebanyak 1 tablet. Penggunaan golongan neuroprotektif dapat digunakan sebanyak 2 kali dalam sehari dikarenakan dosis yang digunakan oleh citicoline adalah $500 \mathrm{mg}$ - $1000 \mathrm{mg}$ per hari (PERDOSSI, 2011).

Cara penggunaan obat yang paling banyak digunakan untuk penyakit stroke iskemik pada pasien rawat jalan di Rumah Sakit di Kota Sungailiat tahun 2018 secara oral. Pasien yang mendapatkan terapi stroke iskemik menerima obat dalam bentuk sediaan tablet. Pemberian secara oral menjadi pilihan dikarenakan pasien rawat jalan akan mudah mengkonsumsi obat tanpa harus menggunakan tenaga medis. Pemberian obat secara oral adalah rute pemberian yang paling mudah dan biasa digunakan karena kemudahan pemberiannya, kepatuhan pasien yang tinggi, dan efektif (Vieth et al. 2004). Selain itu, penggunaan secara oral tidak perlu latihan khusus terkait penggunaannya. Obat stroke iskemik yaitu citicoline dan piracetam pada penggunaan oral, memiliki bioavalabilitas yang baik yaitu hampir $100 \%$ dan merupakan senyawa yang mudah larut dalam air dan bersifat mudah larut dalam air (Doijad dkk., 2012).

\section{SIMPULAN}

Pola peresepan yang meliputi nama obat, bentuk sediaan, kekuatan sediaan, dosis obat, jumlah obat, aturan pemakaian dan cara penggunaan yang diberikan pada pasien stroke iskemik rawat jalan Rumah Sakit di Kota Sungailiat tahun 2018 sudah sesuai dengan guidelines stroke yang ada.

\section{SARAN}

Adapun saran untuk penelitian selanjutnya adalah sebagai berikut:

Melakukan penelitian lebih lanjut tentang stroke iskemik dengan metode prospektif dan pola peresepan untuk penyakit tidak menular (PTM) yang lain.

Rumah sakit selalu memperhatikan ketersediaan stok obat clopidogrel $75 \mathrm{mg}$ dan citicoline $500 \mathrm{mg}$ agar tidak terjadi kekosongan obat sehingga dapat meningkatkan kualitas pelayanan kesehatan di Rumah Sakit. 
Dinas kesehatan memberikan penyuluhan kepada para penderita stroke iskemik terkait pola hidup yang harus dijalani ketika sudah terdiagnosa stroke dan pola konsumsi obat yang benar, teratur dan disiplin.

\section{UCAPAN TERIMA KASIH}

Puji Syukur kehadirat ALLAH SWT, penulis dapat menyelesaikan penyusunan penelitian yang berjudul "Pola Peresepan Penyakit Stroke Iskemik Pasien Rawat Jalan Rumah Sakit di Kota Sungailiat". Penulis menyadari penelitian ini tidak akan selesai tanpa bantuan berbagai pihak. Penulis mengucapkan terima kasih kepada Kepala Rumah Sakit di Kota Sungailiat yang sudah memfasilitasi penelitian sehingga penulis dapat menyelesaikan penelitian ini. Terima kasih pada segenap pengelola Jurnal JKP yang sudah melakukan review terhadap penelitian ini.

\section{DAFTAR PUSTAKA}

Adibhatla, R. M., Hatcher, J. F., 2005, Cytidine 5- Diphosphocholine (CDP-choline) in Stroke and other CNS disorders, Journal Neurochemistry Res., 70: 133-139.

Ansel. (2008). Pengantar Bentuk Sediaan Farmasi Edisi VI.( F. Ibrahim). Jakarta, ID: UI Press

Clark WM, Williams BJ, Selzer KA, Zweifler RM,Sabounjian LA, Gammans RE, 1999, A randomized efficacy trial of citicoline in patients with acute ischemic stroke,Stroke, 30(12). 2592.

Destianti, D., Rina, S., Eli ,H., Ellin, F., \& Syahrul, N. (2016). Evaluasi Penggunaan Obat Antihipertensi pada Pasien Metode ATC/DDD. Farmaka, 2, 1-8.

Doijad, R.C., Pathan, A.B., Pawar, N.B., Baraskar, S.S., Maske, V.D. dan Gaikwad, S.L., 2012. Therapeutic applications of citicoline and piracetam as fixed-dose combination. Journal of Pharma and BioScience, 2(12):15-20.

Fagan, S.C. \& Hess, D.C. (2008). Stroke. In: Wells, Barbara G., Dipiro, J.T.,
Schwinghammer, T.L. \& Dipiro, C.V. A Pharmacotherapy: Pathophysiologic Approach, 7th Ed. New York, NY: The McGraw Hills, 373-381.

Febriola, N. T. F. (2019). Drug Related Problem pada pasien stroke iskemik rawat inap di RSUD Ir.Soekarno Sukoharjo tahun 2017. Surakarta, ID: Universitas Muhammadiyah Surakarta.

Ferliyanti. (2019). Komunikasi pribadi kepala instalasi farmasi RSUD Depati Bahrin Sungailiat. Dilakukan di Sungailiat tanggal 22 Januari 2019.

Gouya, G., Arrich, J., Wolzt, M., Huber, K., Verheugt, F.W.A., Gurbel, P.A., et al., 2014. Antiplatelet Treatment for Prevention of Cerebrovascular Events in Patients with Vascular Diseases A Systematic Review and Meta-Analysis. Stroke, 45: 492-503.

Kemenkes RI. (2017). Profil Kesehatan Indonesia Tahun 2016. Jakarta, ID: Kementerian Kesehatan Republik Indonesia.

Kemenkes RI. 2013. Riset Kesehatan Dasar, RISKESDAS. Jakarta, ID: Balitbang Kemenkes RI

Kemenkes RI.2018 Riset Kesehatan Dasar, RISKESDAS. Jakarta, ID: Balitbang Kemenkes RI

Kessler, J., Theil, A., Karbe, H., Heiss, W., D., 2000, Piracetam Improves Activated Blood Flow and Facilitates Rehabilitation of Poststroke Aphasic Patient, American Heart Association, 31: 2112.

Mahapatra, A. K., Agrawal, D., Kumar, R., 2008, Review Article: Minor Head Injury, Indian Journal of Neurotrauma (IJNT), 5 (2): 59-62

PERDOSSI. (2011). Guidelines Stroke 2011. Jakarta, ID: Perhimpunan Dokter Spesialis Saraf Indonesia. 
Presly, B. (2014). Terapi pelaksanaan Farmakolog Stroke Iskemik Akut Terapi. Rasional, 12(1), 6-8.

Praja, D. S., Hasmono, D., \& N. Syifa. (2013). Pharmacy. Studi Penggunaan Obat Neuroprotektan pada Pasien Stroke Iskemik (penelitian di RSUD dr.saiful Anwar Malang. 10(02). 152-153

Riyanto. (2011). Metode penelitian kualitatif, kualitatif dan kuantitatif. Yogyakarta, ID.

Vieth, M., Siegel, Mb., Higgs, R. E., \& Watson, I. A., Robertson D. H., et al. 2004. Characteristic physical properties and structural fragments of marketed oral drugs. Journal Medical chem. 47, 224-232

Wahyuddin, M., Arief, N., \& Woro, H. (2013). Perbandingan efek terapi piracetam dan sitikolin terhadap perbaikan fungsi kognitif pasien stroke iskemik. Jurnal Manajemen dan Pelayanan Farmasi. Universitas Gadjah Mada.Vol.3 No.4. Yogyakarta

Wahjoepramono, E. J., (2005). Stroke Tata Laksana Fase Akut. Jakarta, ID: Universitas Pelita Harapan

Wang, Y., Wang, Y., Zhao, X., Liu, L., Wang, D.,Wang, C., et al., 2013, Clopidogrel with Aspirin in Acute Minor Stroke or Transient Ischemic Attack. New England Journal of Medicine, 369: 11-19.

WHO. (1993). How to Investigate the Drug Use in Health Facilities, Selected Drug Use Indikator, 9-12. Geneva: World Health Organization 